\title{
Minimal residual disease- and graft-vs.-host disease-guided multiple consolidation chemotherapy and donor lymphocyte infusion prevent second acute leukemia relapse after allotransplant
}

Chen-Hua Yan ${ }^{1,2}$, Yu Wang ${ }^{1,2}$, Jing-Zhi Wang ${ }^{1}$, Yu-Hong Chen', Yao Chen ${ }^{1}$, Feng-rong Wang ${ }^{1}$, Yu-Qian Sun ${ }^{1}$, Xiao-Dong Mo ${ }^{1}$, Wei Han ${ }^{1}$, Huan Chen ${ }^{1}$, Xiao-hui Zhang ${ }^{1,2}$, Lan-Ping $\mathrm{Xu}^{1}$, Kai-Yan Liu ${ }^{1,2}$ and Xiao-Jun Huang ${ }^{1,2^{*}}$

\begin{abstract}
Background: Persons with acute leukemia relapsing after allotransplant and who respond to anti-leukemia interventions are at high risk of a second relapse. We studied the impact of minimal residual disease (MRD)- and graft-vs.-host disease (GvHD)-guided multiple consolidation chemotherapy and donor lymphocyte infusions (DLIs) to prevent second relapse in patients with acute leukemia relapsing post-transplant and who achieved complete remission after induction chemotherapy and DLI.

Methods: Forty-seven subjects with acute leukemia relapsing after an allotransplant and who achieved complete remission after post-relapse induction chemotherapy and DLI were eligible. The use of consolidation chemotherapy and DLI was guided by the results of MRD testing and whether or not DLI caused acute and/or chronic GVHD. Outcomes were compared with those of 34 similar historical controls who did not receive consolidation chemotherapy and DLIs after induction chemotherapy and DLI.

Results: One-year cumulative incidence of relapse (CIR; $22 \% 95 \%$ confidence interval (10, $35 \%)$ vs. $56 \%$ (39, $73 \%$ ); $P<0.0001)$, leukemia-free survival (LFS; $71 \%(57,84 \%)$ vs. $35 \%(19,51 \%) ; P<0.0001)$, and survival $(78 \%(66,90 \%)$ vs. $44 \%(27,61 \%) ; P<0.0001)$ was significantly better in subjects than controls. In multivariate analyses, no chronic GvHD after therapy (hazard ratio $(H R)=3.56(1.09,11.58) ; P=0.035)$ and a positive MRD test after therapy $(H R=21.04$ $(4.44,94.87) ; P<0.0001)$ were associated with an increased CIR.
\end{abstract}

Conclusion: These data suggest MRD- and GVHD-guided multiple consolidation chemotherapy and DLIs reduce CIR and increase LFS and survival compared with controls in persons relapsing after allotransplant for acute leukemia.

Trial registration: ChiCTR-ONC-12002912. Donor lymphocyte infusion for the treatment of leukemia relapse following allogeneic hematopoeitic stem cell transplant.

Keywords: Allogeneic hematopoietic stem cell transplant, Leukemia relapse, Acute leukemia, Donor lymphocyte infusions, Minimal residual disease, Graft-vs.-host disease

\footnotetext{
* Correspondence: huangxiaojun@bjmu.edu.cn

${ }^{1}$ Beijing Key Laboratory of Hematopoietic Stem Cell Transplantation, Peking

University Institute of Hematology, Peking University People's Hospital, Xi

Zhimen South Street No. 11, Beijing 100044, China

${ }^{2}$ Collaborative Innovation Center of Hematology, Xi Zhimen South Street No.

11, Beijing 100044, China
} 


\section{Background}

Leukemia relapse is still a major problem after allotransplants for acute leukemia [1, 2]. Therapy of posttransplant relapse includes stopping immune suppression and giving anti-leukemia chemotherapy and donor lymphocyte infusions (DLIs). Schmid et al. reported a $34 \%$ complete remission rate from chemotherapy and DLI in 171 persons relapsing after an allotransplant for acute leukemia with a 2-year survival of $21 \pm 3 \%$ SD [3]. We recently reported a 64\% (95\% confidence interval (CI), 50-76\%) complete remission rate and $36 \%$ (23, $49 \%$ ) 1-year leukemia-free survival (LFS) and $20 \%(9,33 \%)$ 2-year LFS in 50 persons relapsing after an allotransplant [4]. Clearly, these results need improvement.

In persons receiving an allotransplant for acute leukemia, we reported an association between a positive minimal residual disease (MRD)-test after transplant and an increased risk of subsequent relapse [5-8]. Furthermore, in persons relapsing after an allotransplant and who achieve complete remission after induction chemotherapy and DLIs, the association between a positive MRD test and an increased risk of a second relapse was also reported in our previous study [4]. Also, persons developing chronic GvHD after receiving DLI for leukemia relapse after a first allotransplant have a lower likelihood of a second relapse compared with similar persons not developing chronic GvHD [4]. And, Mo et al. [9] also reported persons with chronic GvHD after DLI was associated with a greater frequency of a negative MRD test and lower likelihood of subsequent relapse compared with similar persons not developing chronic GvHD. Based on these data, we designed a study to determine whether giving additional consolidation chemotherapy and DLI might decrease likelihood of second relapse in persons without chronic GvHD or with a positive MRD test after initial post-relapse therapy with induction chemotherapy and DLI.

\section{Methods \\ Eligibility}

From January 1, 2013, to February 28, 2015, subjects receiving non-T cell-depleted an allotransplant at Peking University Institute of Hematology were eligible if they met the following criteria: (1) acute leukemia without $\mathrm{t}(9 ; 22)$; (2) relapse after an allotransplant; (3) had full or partial-donor chimerism; and (4) received re-induction chemotherapy and DLI and achieved a complete remission. The study was approved by the Ethics Committee of Peking University People's Hospital, and written informed consent was obtained from all subjects in accordance with the Declaration of Helsinki. The study is registered at http://www.chictr.org.cn as ChiCTR-ONC-12002912.

\section{Study-design and protocol Subjects}

From January 1, 2013, to February 28, 2015, 87 consecutive subjects ages $4-58$ years relapsing after an allotransplant were screened for eligibility. Eight received only supportive care and nine received chemotherapy but not DLI because no donor was available $(N=6)$ or because there were no residual donor cells at time of relapse $(N=3)$. Forty-seven $(67 \%(56,77 \%))$ of the remaining 70 subjects receiving re-induction chemotherapy and DLI to control relapse post-transplant achieved a complete remission and were eligible for this study. Controls were selected from among 69 similar subjects relapsing after allotransplant at our center from January 1, 2000, to December 31, 2008. We excluded five receiving only supportive care, seven who did not receive DLI because no donor was available $(N=4)$ or because there were no residual donor cells at time of relapse $(N=3)$, and three who received a second allotransplant. In the remaining 54 subjects receiving re-induction chemotherapy and DLI, 34 (63\% (50, $75 \%))$ subjects achieved a complete remission and served as controls.

\section{Therapy-protocol}

Post-transplant immune suppression was discontinued immediately upon relapse. All subjects then received induction chemotherapy (see below). DLI was given 48-72 h after completing chemotherapy (see below). Subjects not achieving a complete remission after a second course of induction chemotherapy and DLI were excluded. Subjects achieving a complete remission had MRD testing at $1,2,3,6,9$, and 12 months and at 6-month intervals thereafter. Consolidation chemotherapy and additional DLIs (see below) were given based on the results of MRD testing and whether the subjects developed GvHD. Subjects with a positive MRD test received consolidation chemotherapy and DLIs monthly until the MRD test became negative. If white blood cells (WBC) counts recovered within 30 days, consolidation chemotherapy and DLIs were given monthly until MRD test became negative; if WBC counts recovered after 30 days, consolidation chemotherapy and DLIs were given when WBC counts recovered post-chemotherapy. Subjects with a negative MRD test and no GvHD received consolidation chemotherapy and DLIs at 3, 6, and 9 months. If MRD test was persistently negative and GvHD never resolved, consolidation chemotherapy and DLI was not given. If the MRD test was persistently negative but GvHD resolved, consolidation chemotherapy and DLI were given at 6 months. If the MRD test was positive again and GvHD resolved, consolidation chemotherapy and DLI were given monthly until the MRD test became negative again. If MRD test was positive again but GvHD never resolved, consolidation chemotherapy without DLI was given 
monthly until the MRD test became negative again. Interventions were continued until 1 year after achieving complete remission (Fig. 1a).

Induction chemotherapy in persons with acute myeloid leukemia (AML) was homoharringtonine, $2 \mathrm{mg} / \mathrm{mE}+2 /$ day for 5 days, aclacinomycin, $10 \mathrm{mg} / \mathrm{mE}+2 /$ day for 5 days and cytarabine, $100 \mathrm{mg} / \mathrm{mE}+2 /$ day for 5 days (HAA). Induction chemotherapy in persons with acute lymphoblastic leukemia (ALL) was cyclophosphamide, $800 \mathrm{mg} / \mathrm{mE}+2 /$ day for 2 days, vincristine $1 \mathrm{mg} / \mathrm{mE}+2$ / day on day 1 , daunorubicin, $40 \mathrm{mg} / \mathrm{mE}+2 /$ day for 3 days, and prednisone, $60 \mathrm{mg} /$ day for 7 days (CODP). Subjects not achieving a complete remission after the first course of induction chemotherapy and DLI received a second course of induction chemotherapy with HAA or fludarabine, $30 \mathrm{mg} / \mathrm{mE}+2 /$ day for 5 days, cytarabine, 1 g every $12 \mathrm{~h}$ for 10 doses and granulocyte-colony stimulating factor (G-CSF), $300 \mu \mathrm{g} /$ day for 6 days (FLAG) in subjects with AML and CODP or methotrexate (MTX), $1 \mathrm{~g} / \mathrm{mE}+$ 2/day for 1 days and pegaspargase, $2000 \mathrm{U} / \mathrm{mE}+2 /$ day for 1 day in subjects with ALL. Consolidation chemotherapy in persons with AML was AA or HAA. Consolidation chemotherapy in persons with ALL was CODP or MTX, $1 \mathrm{~g} / \mathrm{mE}+2 /$ day for 1 day.

DLIs used G-CSF mobilized blood cells followed by cyclosporine (CSA) or MTX to prevent GvHD. Details are reported [10, 11]. Median dose of mononuclear cells (MNC) for each infusion was $1.0 \times 10 \mathrm{E}+8 / \mathrm{kg}$. Subjects could receive up to four courses of DLIs. Subjects receiving
DLIs from a human leucocyte antigen (HLA)-haplotypematched donor or an HLA-matched unrelated donor received CSA for 6 weeks after each infusion to prevent GvHD [10]. Subjects receiving DLIs from a HLA-identical related donor received CSA or MTX for 2-4 weeks after each infusion to prevent GvHD [11]. In subjects receiving DLI from a HLA-identical related donor with prior $\geq$ grade 2 acute GvHD or $\geq$ moderate chronic GvHD received CSA after DLI whereas others received MTX. The starting dose of CSA was $2.5 \mathrm{mg} / \mathrm{kg} /$ day and the dose was adjusted to maintain a plasma concentration $150-250 \mathrm{ng} / \mathrm{ml}$. MTX, $10 \mathrm{mg}$, was given on days $+1,+4,+8,+15$, and +21 .

\section{MRD testing}

We used to two strategies to test for MRD in bone marrow samples: (1) aberrant leukemia-associated immune phenotypes (LAIPs) detected by four-color flow cytometry (FCM) and (2) WT1 messenger RNA (mRNA) levels detected by polymerase chain reaction (PCR) [5-8, 12]. LAIPs were detected by four-color FCM. Different antibody combinations were used in B-ALL, T-ALL, and AML as described $[5,12]$. $7.5 \times 10 \mathrm{E}+5-1 \times 10 \mathrm{E}+6$ events were routinely analyzed. FCM-positive was defined as $>0.01 \%$ of cells with a LAIPs phenotype in $\geq 1$ bone marrow samples. Sensitivity was $79 \%$ and specificity was $85 \%$ for persons with ALL [5]. WT1 mRNA level was evaluated by TaqMan-based RQPCR technology as described [6]. WT1-positive was defined as a transcript level $>0.60 \%$ in $\geq 1$ bone marrow samples. Sensitivity was $69 \%$ and specificity was $91 \%$ for persons

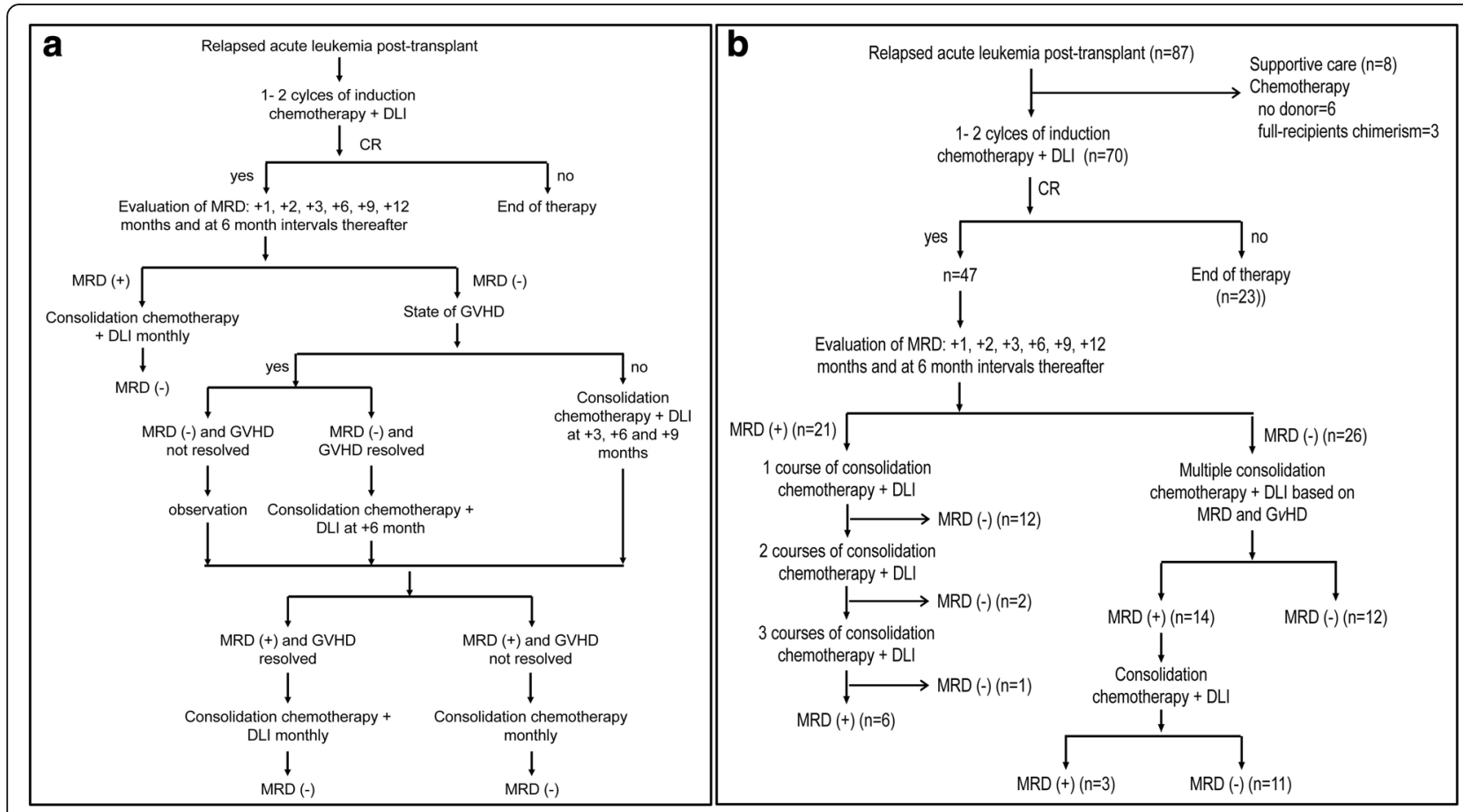

Fig. 1 The diagram of intervention strategy. a The diagram of intervention strategy. $\mathbf{b}$ The diagram of patient subgroups 
with AML [7]. Subjects with a positive LAIP or WT1 test were declared MRD test positive [7, 8].

\section{Chimerism analysis}

Chimerism analysis was performed by using DNA fingerprinting of short tandem repeats (STRs) from whole cell population in peripheral blood samples. If patients received transplant from sex-mismatched donors, chimerism analysis was also performed by using fluorescent in situ hybridization (FISH) for sex chromosomes in the bone marrow samples. Evaluations of chimerism were performed at the time of relapse post-transplant and at $1,2,3,6,9$, and 12 months after induction chemotherapy and at 6-month intervals thereafter.

\section{Transplants}

Details of transplants including conditioning regimen, graft composition, GvHD prophylaxis, and supportive care are described [13-15]. Recipients of HLA-identical related transplants received cyclophosphamide, $1.8 \mathrm{~g} / \mathrm{mE}+2 /$ day, for 2 days and 1 dose of 7.7 Gy total body radiation at $3.2 \mathrm{cGy} / \mathrm{min}$ or busulfan, $3.2 \mathrm{mg} / \mathrm{kg} /$ day IV for 3 days, and cyclophosphamide. Recipients of HLA-haplotypematched related transplants and of HLA-matched unrelated transplants also received anti-human thymocyte immunoglobulin (ATG), $2.5 \mathrm{mg} / \mathrm{Kg} / \mathrm{d}$ IV days -5 to -2 (Genzyme Corp, Boston, MA, USA). Grafts consisted of G-CSF mobilized bone marrow cells and peripheral blood cells. CSA, mycophenolate mofetil, and shortterm MTX were given to prevent or modify GvHD.

\section{Definitions}

Given that thrombocytic recovery could be postponed by factors other than leukemia and cytotoxic therapy (i.e., GvHD, virus, drugs), complete remission was defined as less than $5 \%$ bone marrow blasts without evidence of dysplasia in bone marrow, no myeloblasts with Auer rods, no extra-medullary leukemia, and $\mathrm{ANC} \geq 1 \times 10 \mathrm{E}+9 / \mathrm{L}$. Leukemia relapse was defined as recurrence of $\geq 5 \%$ bone marrow blasts or of $\geq 1$ extra-medullary sites of leukemia. Neutrophil recovery was defined as an absolute neutrophil count (ANC) $\geq 0.5 \times 10 \mathrm{E}+9 / \mathrm{L}$, and the time of neutrophil recovery was defined as the interval from the end of chemotherapy to the date of neutrophil recovery. Platelet recovery was defined as a platelet count $\geq 20 \times 10 \mathrm{E}+9 / \mathrm{L}$ for 7 consecutive days without transfusions, and the time of platelet recovery was defined as the interval from the end of chemotherapy to the date of platelet recovery. Survival was defined as interval from complete remission after post-relapse induction chemotherapy to death from any cause. LFS was defined as interval from the same start point to leukemia relapse or death whichever occurred first. Grading of acute GvHD and chronic GvHD used published criteria $[16,17]$.

\section{Statistics}

The study was powered to detect $60 \%$ LFS based on a reference rate of $35 \%$ at 1 year derived using data from our center (unpublished). The primary end point was 1-year LFS. Secondary endpoints included incidence of acute and chronic GvHD, 1-year cumulative incidence of relapse (CIR), and survival.

CIRs, transplant-related mortality (TRM), and GvHD were calculated using a competing risk model. LFS and survival were calculated using the Kaplan-Meier method and compared using the log-rank test. Univariate analyses were performed using the $X^{2}$ test for categorical variables and the Mann-Whitney test for continuous variables. Multivariate analyses were performed using a Cox proportional hazards model. Potential interactions were tested, screened, and extracted from the analysis. Endpoint of follow-up for surviving subjects was February 28,2016 . Unless specified, all $P$ values were two-sided and a $P$ value $<0.05$ was considered significant. SPSS and $R$ software packages were used for data analyses.

\section{Results \\ Subject variables}

Subject-related variables of trial subjects and controls are displayed in Table 1. Although most were similar, trial subjects were more likely to receive a HLA-haplotypematched transplant (66 \% (52, $78 \%$ ) vs. $56 \%$ (39, $71 \%$ ); $P=0.037$; Table 1). Besides, in 47 trial subjects achieving complete remission, platelet did not achieve $100 \times 10 \mathrm{E}+$ $9 / \mathrm{L}$ at the time of complete remission in 7 subjects, and in 34 controls achieving complete remission, platelet did not achieve $100 \times 10 \mathrm{E}+9 / \mathrm{L}$ in 6 controls.

Twenty-six trial subjects (55\% (41, $69 \%)$ ) were MRD test negative when they achieved a complete remission. Twelve others became MRD test negative after the first course of consolidation chemotherapy and DLI. Two more subjects became MRD test negative after the second course of consolidation chemotherapy and DLI, and one subject became MRD test negative after a third course of consolidation chemotherapy and DLI. Fourteen of the 26 subjects $(54 \%(35,71 \%))$ with a negative MRD test when they achieved remission had $\geq 1$ subsequent positive MRD tests. All received consolidation chemotherapy and DLIs, and 11 became MRD test negative. Finally, 38 trial subjects $(81 \%(67,90 \%))$ were continuously MRD test negative (Fig 1b). Twenty-one trial subjects received one course of consolidation chemotherapy and DLI, 18 received two courses of consolidation chemotherapy and DLI, 7 received three courses of consolidation chemotherapy and DLI, and 1 received four courses of consolidation chemotherapy and DLI (Table 1). All trial subjects achieved neutrophil recovery with a median time of 17 days (range, 10-30 days). Forty-five trial subjects achieved platelet recovery with a median 
Table 1 Characteristics of patients in study group and historical group $(n=81)$

\begin{tabular}{|c|c|c|c|}
\hline Characteristics & Study group & Historical group & $P$ \\
\hline Patients' number & 47 & 34 & \\
\hline Age (years, range) & $28(4-58)$ & $25(7-57)$ & 0.696 \\
\hline Gender & & & 0.294 \\
\hline Male (\%) & $29(62)$ & $17(50)$ & \\
\hline Female (\%) & $18(38)$ & $17(50)$ & \\
\hline Diagnosis (\%) & & & 0.300 \\
\hline Acute myeloid leukemia & $25(53)$ & $22(65)$ & \\
\hline Acute lymphoid leukemia & $22(47)$ & $12(35)$ & \\
\hline Remission state pre-HSCT (\%) & & & 0.154 \\
\hline CR1 & $39(83)$ & $25(73)$ & \\
\hline CR2 & $5(11)$ & $9(27)$ & \\
\hline CR3 & $2(4)$ & $0(0)$ & \\
\hline NR & $1(2)$ & $0(0)$ & \\
\hline Cytogenetic subgroups $^{\mathrm{a}}(\%)$ & & & 0.285 \\
\hline Intermediate & $30(64)$ & $18(53)$ & \\
\hline Poor & $10(21)$ & $6(18)$ & \\
\hline Not available & $7(15)$ & $10(29)$ & \\
\hline Numbers of induction chemotherapies (\%) & & & 0.214 \\
\hline$\leq 2$ & $39(85)$ & $25(74)$ & \\
\hline$>2$ & $7(15)$ & $9(26)$ & \\
\hline Donor types (\%) & & & 0.037 \\
\hline HLA-identical related & $11(23)$ & $15(44)$ & \\
\hline Haploidentical related & $31(66)$ & $19(56)$ & \\
\hline Unrelated & $5(11)$ & $0(0)$ & \\
\hline HLA-mismatch (\%) & & & 0.230 \\
\hline 0 locus mismatch & $4(11)$ & $0(0)$ & \\
\hline 1 locus mismatch & $3(8)$ & $4(21)$ & \\
\hline 2 locus mismatch & $10(28)$ & $7(37)$ & \\
\hline 3 locus mismatch & $19(53)$ & $8(38)$ & \\
\hline Donor-patient sex match (\%) & & & 0.377 \\
\hline Female-female & $3(6)$ & $6(18)$ & \\
\hline Female-male & $13(28)$ & $7(21)$ & \\
\hline Male-male & $18(38)$ & $14(41)$ & \\
\hline Male-female & $13(28)$ & $7(21)$ & \\
\hline ABO match $(\%)$ & & & 0.994 \\
\hline Match & $31(66)$ & $22(65)$ & \\
\hline Major mismatch & $6(13)$ & $5(15)$ & \\
\hline Minor mismatch & $6(13)$ & $4(12)$ & \\
\hline Major and minor mismatch & $4(9)$ & $3(9)$ & \\
\hline Conditioning regimen (\%) & & & 0.635 \\
\hline TBI-based & $3(6)$ & $1(3)$ & \\
\hline Bu-based & $44(94)$ & $33(97)$ & \\
\hline Acute GvHD of grades 2-4 pre-DLI & $14(30)$ & $9(27)$ & 0.744 \\
\hline Acute GvHD of grades 3-4 pre-DLI (\%) & $4(9)$ & $0(0)$ & 0.135 \\
\hline
\end{tabular}


Table 1 Characteristics of patients in study group and historical group $(n=81)$ (Continued)

\begin{tabular}{|c|c|c|c|}
\hline Chronic GvHD pre-DLI (\%) & $10(21)$ & $12(35)$ & 0.162 \\
\hline Moderate or severe chronic GvHD pre-DLI (\%) & $4(9)$ & $6(18)$ & 0.307 \\
\hline Interval from HSCT to relapse (day) (range) & $204(39-2180)$ & $241(40-2405)$ & 0.737 \\
\hline BM blasts at the time of relapse (\%) (range) & $29(7-93)$ & $28(9-92)$ & 0.513 \\
\hline Chimerism at the time of relapse (\%) & & & 0.294 \\
\hline Full-donor chimerism & $34(72)$ & $28(82)$ & \\
\hline Partial-donor chimerism & $13(28)$ & $6(18)$ & \\
\hline Times of DLI after induction chemotherapy plus DLI & & & NA \\
\hline 1 & $21(45)$ & $0(0)$ & \\
\hline 2 & $18(38)$ & $0(0)$ & \\
\hline 3 & $7(15)$ & $0(0)$ & \\
\hline 4 & $1(2)$ & $0(0)$ & \\
\hline MNCs in DLI $\left(\times 10^{8} / \mathrm{kg}\right.$, range $)$ & $1.00(1.00-1.50)$ & $1.00(0.70-1.70)$ & 0.957 \\
\hline $\mathrm{CD}^{+}$cells in $\mathrm{DLI}\left(\times 10^{8} / \mathrm{kg}\right.$, range $)$ & $0.34(0.15-0.64)$ & $0.37(0.15-0.74)$ & 0.653 \\
\hline $\mathrm{CD}^{+}$cells in $\mathrm{DLI}\left(\times 10^{8} / \mathrm{kg}\right.$, range $)$ & $0.20(0.10-0.42)$ & $0.23(0.09-0.31)$ & 0.732 \\
\hline $\mathrm{CD}^{+}$cells in $\mathrm{DLI}\left(\times 10^{8} / \mathrm{kg}\right.$, range $)$ & $0.12(0.06-0.28)$ & $0.14(0.05-0.31)$ & 0.657 \\
\hline $\mathrm{CD} 4^{+}$cells in DLI $\left(\times 10^{8} / \mathrm{kg}\right.$, range $)$ & $0.26(0.04-0.48)$ & $0.29(0.09-0.61)$ & 0.432 \\
\hline $\mathrm{CD} 4^{+}$cells in DLI $\left(\times 10^{6} / \mathrm{kg}\right.$, range $)$ & $0.48(0.14-1.44)$ & $0.54(0.12-1.58)$ & 0.354 \\
\hline
\end{tabular}

HSCT hematopoietic stem cell transplantation, $C R 1$ first complete remission, CR2 second complete remission, CR3 third complete remission, NR non-remission, $H L A$ human leucocyte antigen, $T B I$ total body irradiation, Bu busulfan, GvHD graft-vs.-host disease, $D L I$ donor lymphocyte infusion, $B M$ bone marrow, NA not available, MNC mononuclear cell

${ }^{a}$ The cytogenetic subgroups are according to the published data $[35,36]$

time of 20 days (range, $8-56$ days). Besides, before disease relapse, 8 trial subjects received chemotherapy and DLI due to a positive MRD test.

\section{Relapse}

Nine subjects had persistent MRD-positive tests including six after multiple courses of consolidation chemotherapy and DLI and three who were transiently MRD test negative. Seven relapsed and two other died of TRM. This contrasts with relapse in only 7 of 38 subjects who were consistently MRD test negative $(P=0.001)$. CIR was $22 \%(10,35 \%)$ at 1 year and $35 \%(19,52 \%)$ at 2 years (Table 2 and Fig. 2). In multivariate analyses, no chronic GvHD after DLI $(\mathrm{HR}=3.56(1.09,11.58) ; P=0.035)$ and persistent positive MRD tests after DLI (HR $=21.04$ (4.66, 94.87); $P<0.0001$; Table 3 ) were associated with increased relapse risks.

\section{GvHD}

Nine trial subjects developed acute GvHD after DLI. Of the nine subjects, one developed grade 1 acute GvHD, five developed grade 2 acute GrHD, two developed grade 3 acute GvHD, and one developed grade 4 acute GvHD. Skin affected occurred in eight subjects, liver affected occurred in two, and intestinal tract affected occurred in four. Cumulative incidences of $\geq$ grade 2 acute GvHD and $\geq$ grade 3 acute GvHD were $25 \%$ (15, $39 \%)$ and $11 \%(3,22 \%)$ (Table 2). Besides, 37 subjects developed chronic GvHD, 31 subjects developed $\geq$ moderate chronic GvHD. Of the 37 subjects, 5 had a history of acute GvHD after DLI. Cumulative incidence of chronic GvHD and $\geq$ moderate chronic GvHD at 1 year were $52 \%$ (39, $65 \%)$ and $49 \%(34,64 \%)$ (Table 2). Cumulative

Table 2 Outcomes of patients in study group and historical group $(n=81)$

\begin{tabular}{llll}
\hline Characteristics & $\begin{array}{l}\text { Study } \\
\text { group }\end{array}$ & $\begin{array}{l}\text { Historical } \\
\text { group }\end{array}$ & $P$ \\
\hline Patients' number & 47 & 34 & \\
Cumulative incidence of relapse at 1 year (\%) & 22 & 56 & $<0.0001$ \\
Acute GvHD of grades 2-4 (\%) & 25 & 35 & 0.149 \\
Acute GvHD of grade 3-4 (\%) & 11 & 15 & 0.366 \\
Chronic GvHD (\%) & 52 & 33 & 0.039 \\
Moderate or severe chronic GvHD (\%) & 49 & 23 & 0.005 \\
TRM at 1 year (\%) & 9 & 6 & 0.064 \\
LFS at 1 year (\%) & 71 & 35 & $<0.0001$ \\
Survival at 1 year (\%) & 78 & 44 & $<0.0001$ \\
Causes of mortality $(n)$ & 11 & 30 & \\
Relapse $(n)$ & 7 & 25 & \\
Infection $(n)$ & 3 & 3 & \\
TMA $(n)$ & 1 & 0 & \\
GvHD $(n)$ & 0 & 2 & \\
\hline
\end{tabular}

GVHD graft-vs.-host disease, TRM treatment-related mortality, LFS leukemia-free survival, TMA thrombotic microangiopathy 

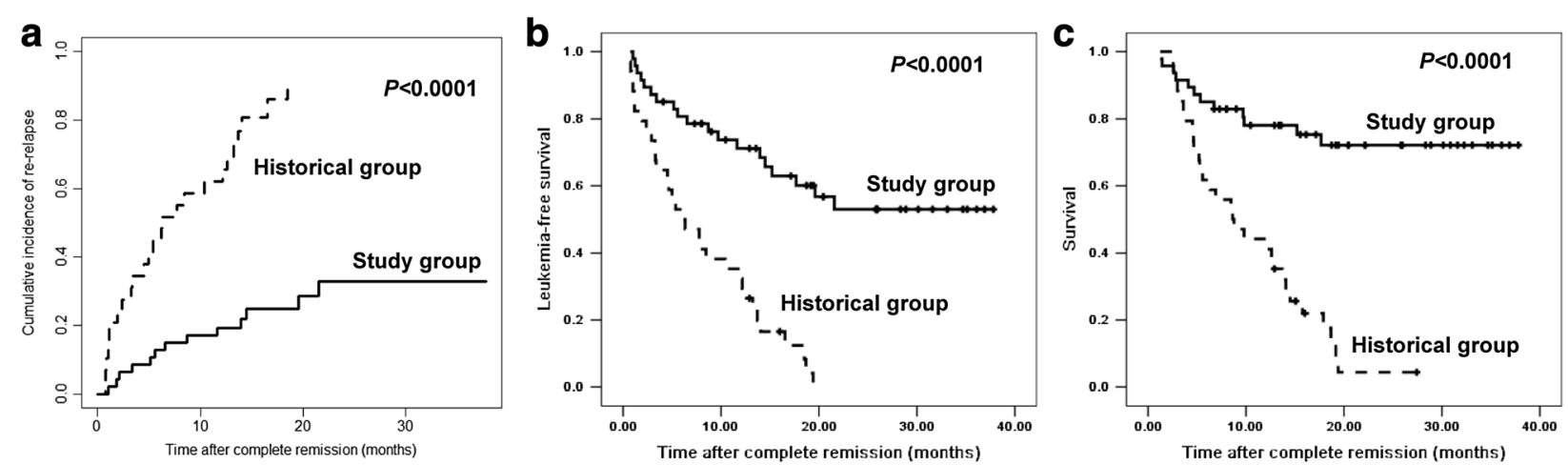

Fig. 2 Comparison of outcomes after complete remission between study group and historical group. a Cumulative incidence of re-relapse after complete remission. b Leukemia-free survival (LFS) after complete remission. c Survival after complete remission. From January 1, 2013, to February 28, 2015, consecutive 47 patients received multiple consolidation chemotherapy and DLI and were finally included in study group. From January 1, 2000, to December 31, 2008, 34 patients only received induction chemotherapy plus DLI and were finally defined as historical group

incidences of chronic and $\geq$ moderate chronic GvHD increased gradually with increased numbers of courses of consolidation chemotherapy and DLI: chronic GvHD: 1 course $35 \%(18,52 \%)$ vs. 2 courses $72 \%(57,86 \%)$ vs. 3-4 courses $100 \%(83,100 \%) ; P=0.002)$ and $\geq$ moderate chronic GvHD: 1 course $30 \%(19,41 \%)$ vs. 2 courses $70 \%(55,85 \%)$ vs. $3-4$ courses $100 \%$ (92, $100 \%) ; P=$ $0.003)$. In contrast, cumulative incidences of $\geq$ grade 2 acute GvHD and $\geq$ grade 3 acute GvHD were not significantly associated with numbers of courses of consolidation chemotherapy and DLI $(P=0.17$ and $P=0.77)$.

\section{LFS and survival}

Eleven trial subjects died, seven died of relapse, three died of infection, and one died of thrombotic microangiopathy. Median LFS was 23 months (range, 4-38 months). LFSs at 1 and 2 years were $71 \%(59,85 \%)$ and $53 \%(37,69 \%)$. Median survival was 32 months (range, 8-38 months). Survivals at 1 and 2 years were $78 \%(66,90 \%)$ and $72 \%$ (59, $86 \%$; Table 2 and Fig. 2).

\section{Comparison of study subjects and controls}

Study subjects had a higher rate of persistent MRDnegative tests than controls (81\% (67, $90 \%)$ vs. $9 \%$ (3, $23 \%) ; P<0.0001)$. CIR in the study cohort was less than in controls $(22 \%(10,35 \%)$ vs. $56 \%(39,73 \%)$; $P<0.0001$ ). Cumulative incidences of $\geq$ grade 2 and $\geq$ grade 3 acute GvHD were similar to controls $(P=0.149$ and $P=0.366)$. One-year cumulative incidences of chronic GvHD (52 \% (39, $65 \%)$ vs. $33 \%(12,54 \%) ; P=0.039)$ and $\geq$ moderate chronic GvHD (49 \% (34, 64 \%) vs. $23 \%(8,38 \%) ; P=0.005)$ was significantly higher in subjects vs. control. One-year LFS was significantly better in subjects vs. controls $(71 \%(57,84 \%)$ vs. $35 \%$ $(19,51 \%), P<0.0001)$. One-year survival was also better $(78 \%(66,90 \%)$ vs. $44 \%(27,61 \%) ; P<0.0001$; Table 2 and Fig. 2).

\section{Discussion}

We found MRD test results and GvHD-guided multiple consolidation chemotherapy and DLIs reduced CIR and improved LFS and survival compared with historical controls in patients with relapsed acute leukemia after allo-hematopoietic stem cell transplantation (HSCT). This was probably due to that the use of multiple consolidation chemotherapy and DLIs after induction chemotherapy and DLI could make more patients achieve and maintain a persistent negative MRD test. Although induction chemotherapy and DLI could make patients achieve complete remission in patients with relapsed acute leukemia after transplant, only $55 \%$ of patients achieved a negative MRD test, and $54 \%$ of these patients had subsequent positive MRD tests. But, after multiple consolidation chemotherapy and DLIs, $81 \%$ of patients finally maintained a negative MRD test, compared with a $9 \%$ of negative MRD test rate in historical control $(P<0.0001)$. Many studies already report a positive MRD test is associated with an increased relapse risk post-transplant [5-7, 12, 18, 19]. As well, based on the results of MRD tests, preemptive use of DLI could make patients achieve a negative MRD test and prevent relapse post-transplant in patients with standard risk acute leukemia [8]. Besides, multiple consolidation chemotherapy and DLIs also induced chronic GvHD and stronger graft-vs.-leukemia (GvL) effects. Our present study suggested that the incidence of chronic GvHD in study group was significantly higher than that in historical control (52 vs. $33 \%, P=0.039$ ), as well as, the incidence of chronic GvHD post-DLI increased gradually with increased numbers of courses of consolidation chemotherapy and DLI $(P=0.002)$. Many researchers have already demonstrated that the development of chronic GvHD post-DLI was a favorable factor of CIR and survival in patients with relapsed acute leukemia after allo-HSCT [3, 4, 20, 21]. Therefore, all of these data 
Table 3 Univariate and multivariate analyses for re-relapse after complete remission

\begin{tabular}{|c|c|c|}
\hline Characteristics & Relapse & \\
\hline Univariate analysis & $P$ & \\
\hline Age & 0.468 & \\
\hline Gender & 0.521 & \\
\hline Diagnosis & 0.211 & \\
\hline Remission status pre-HSCT & 0.748 & \\
\hline Cytogenetic subgroups $^{a}$ & 0.294 & \\
\hline Numbers of induction chemotherapies & 0.654 & \\
\hline Donor types & 0.735 & \\
\hline HLA-mismatch & 0.090 & \\
\hline Donor-patient sex match & 0.932 & \\
\hline $\mathrm{ABO}$ match & 0.154 & \\
\hline Conditioning regimen & 1.000 & \\
\hline Acute GvHD of grades 2-4 pre-DLI & 0.726 & \\
\hline Chronic GvHD pre-DLI & 0.703 & \\
\hline Interval from HSCT to relapse & 0.695 & \\
\hline BM blasts at the time of relapse & 0.443 & \\
\hline Chimerism at the time of relapse & 0.467 & \\
\hline MNCs in DLI & 0.388 & \\
\hline $\mathrm{CD}^{+}$cells in $\mathrm{DLI}$ & 0.252 & \\
\hline $\mathrm{CD}^{+}$cells in DLI & 0.242 & \\
\hline $\mathrm{CD}^{+}$cells in $\mathrm{DLI}$ & 0.348 & \\
\hline CD14 ${ }^{+}$cells in DLI & 0.209 & \\
\hline $\mathrm{CD}_{4} 4^{+}$cells in DLI & 0.817 & \\
\hline Acute GVHD of grades 2-4 post-DLI & 0.413 & \\
\hline Chronic GvHD post-DLI & 0.002 & \\
\hline Persistent MRD-positive state post-DLI & 0.001 & \\
\hline Multivariate analysis & $P$ & $H R$ \\
\hline Persistent MRD-positive state post-DLI & $<0.0001$ & 21.04 \\
\hline No chronic GvHD post-DLI & 0.035 & 3.56 \\
\hline
\end{tabular}

HSCT hematopoietic stem cell transplantation, HLA human leucocyte antigen, GVHD graft-vs.-host disease, DLI donor lymphocyte infusion, BM bone marrow, MNC mononuclear cell, MRD minimal residual disease

${ }^{\text {aT }}$ The cytogenetic subgroups are according to the published data $[35,36]$

suggested that the application of multiple consolidation chemotherapy and DLIs after induction chemotherapy and DLI could prevent the second relapse in patients with relapsed acute leukemia post-transplant, by inducing chronic GvHD and maintaining the negative MRD test.

Severe GvHD is a major risk of multiple consolidation chemotherapy and DLIs, which is usually correlated with higher TRM. However, we found that the incidences of $\geq$ grade 2 acute GvHD and $\geq$ grade 3 acute GvHD in study group were all similar to that in historical control $(P=0.149$ and $P=0.366)$. And ultimately, there was no significant difference in the incidence of TRM between two groups ( 8.8 vs. $6.4 \%, P=0.064)$. A probable reason is due to the application of immunosuppressive agents for 2-4 weeks in patients receiving DLI from HLA-identical related donors and for 6 weeks in patients receiving DLI from haploidentical related donors or unrelated donors. Our previous study suggested that the duration of immunosuppressive agents used after DLI was the only risk factor for the development of $\geq$ grade 3 acute GvHD after DLI $(P=0.018)$ and the cumulative incidence of $\geq$ grade- 3 acute GvHD in patients receiving immunosuppressive agents for $\geq 6$ weeks was only $9.3 \%$ [22]. Besides, the application of immunosuppressive agents for $\geq 6$ weeks after DLI from haploidentical related donors and 2-4 weeks after DLI from HLA-identical related donors could preserve GvL effects at the same time could reduce the incidence of $\geq$ grade 3 acute GvHD after DLI $[10,11]$. As well, our present study also suggested that cumulative incidence of $\geq$ grade 2 acute GvHD and $\geq$ grade 3 acute GvHD were not significantly associated with numbers of courses of consolidation chemotherapy and DLI $(P=0.17$ and $P=0.77$ ), although cumulative incidences of chronic GvHD and $\geq$ moderate chronic GvHD increased gradually with increased numbers of courses of consolidation chemotherapy and DLI $(P=0.003)$. Another probable reason is due to the use of G-CSF mobilized peripheral blood cells instead of unstimulated lymphocytes. Huang et al. $[23,24]$ reported that the application of G-CSF may modulate the polarization of $\mathrm{T}$ cells from a Th1 to a Th2 phenotype and indirectly induce T-cell hyporesponsiveness through the selective increase of $\mathrm{DC} 2$ cells and monocytes and the down-regulation of the CD28/B7 co-stimulatory signal. Moreover, Morris et al. [25] confirmed that using G-CSF during blood cell mobilization augments NK-T-cell-dependent $\mathrm{CD} 8^{+}$cytotoxicity and purportedly separates GvHD and GvL. Our previous study also suggested that compared with chemotherapy and DLI with unstimulated lymphocytes, chemotherapy and G-CSF mobilized peripheral blood cells infusion tended to be associated with a higher complete remission rate (7/9 vs. $3 / 5)$ and lower incidence of $\geq$ grade 3 acute GvHD (0/9 vs. 1/5) in patients with relapsed hematological malignancies after HLAidentical related HSCT [26]. Therefore, although trial subjects received multiple consolidation chemotherapy and DLIs, no subjects died of GvHD. Another risk of multiple consolidation chemotherapy and DLIs is pancytopenia, which usually leads to higher infection-related mortality. Raiola AM et al. [21] found that chemotherapy and DLI with unstimulated lymphocytes was typically associated with a higher incidence of pancytopenia (18/ 100) and a longer duration of pancytopenia (median duration, 90 days). However, chemotherapy and G-CSF mobilized peripheral blood cells infusion was associated with a lower incidence of pancytopenia (2/57) [27]. In this study, all trial subjects achieved neutrophil 
recovery with a median time of 17 day, 45 trial subjects achieved platelet recovery with a median time of 20 days, and only 3 subjects died of infection. All the results confirmed the safety of chemotherapy and DLI which used G-CSF mobilized peripheral blood cells followed by CSA or MTX to prevent GvHD. As well, due to the improvement of diagnosis and treatment of GvHD and infectious disease post-transplant, it also ensured the successful use of multiple consolidation chemotherapy and DLIs. Moreover, because multiple consolidation chemotherapy and DLIs were given based on the results of MRD test and GvHD post-DLI, therefore, it avoided unnecessary TRM while could prevent second relapse in patients with relapsed acute leukemia post-transplant.

Besides, although multiple consolidation chemotherapy and DLIs were given, nine patients were still in a positive MRD test and seven out of nine patients relapsed again post-DLI. Mo et al. [9] also found that early-onset positive MRD test after DLI and persistent positive MRD test after DLI were usually associated with increased relapse risk $(P=0.001)$ and impaired LFS $(P=$ 0.004). Therefore, for those patients with a positive MRD test post-DLI, more intensive therapy should be used so as to make them maintain a persistent negative MRD test. Mo et al. [28] found that in patients who were in a positive MRD test post-transplant, compared with DLI, interferon- $\alpha$ (IFN- $\alpha$ ) could provide comparable rate of negative MRD test, relapse rate $(27.3 \%$ vs. $35.6 \%, P=0.514)$ and disease-free survival (68.2 vs. $60.0 \%, P=0.517$ ). Furthermore, even in patients who had unsatisfied response to DLI, IFN- $\alpha$ could also provide a decreased level of MRD or a negative MRD test [29]. Besides, some articles have already suggested that second transplant could offered a chance of stable remission for patients with acute leukemia relapsing post-transplant and provided a $25-30 \%$ of survival [30, 31]. Moreover, our previous study found that in 24 patients receiving second transplant to treat relapsed acute leukemia post-transplant, although 12 patients had no response to chemotherapy and DLI, second transplant still provided $55.7 \%$ of CIR, $35.1 \%$ of nonrelapse mortality and $30.9 \%$ of survival [32]. Therefore, for patients who had a persistent positive MRD test after two courses of consolidation chemotherapy and DLIs, DLI followed by IFN- $\alpha$ or second transplant were probably alternative methods. This needed to be investigated in future.

In addition, in this study, the complete remission rate $(67 \%, 47 / 60)$ is higher than that in article published before [3]. This is maybe due to the application of chemotherapy before DLI. Collins RH et al. [33] reported that complete remission rate in AML $(n=39)$ and ALL $(n=11)$ patients who had not received chemotherapy before DLI were only 15.4 and $18.2 \%$, respectively. But, in the article from Schmid C et al. [3], $75 \%$ AML patients received chemotherapy before DLI and $35 \%$ patients achieved complete remission. Besides, our previous study also suggested that chemotherapy and DLI provided a $64 \%$ of complete remission rate in subjects with relapsed acute leukemia post-transplant [4]. Another reason is maybe due to the infusion of G-CSF mobilized peripherial blood cells infusion instead of unstimulate donor lymphocytes. Morris et al. [25] confirmed that using G-CSF during blood cell mobilization augments NK-T-celldependent $\mathrm{CD}^{+}$cytotoxicity. As well, our previous study suggested that compared with chemotherapy and DLI with unstimulated lymphocytes, chemotherapy and G-CSF mobilized peripherial blood cells infusion tended to be associated with a higher complete remission rate (7/9 vs. 3/5) in patients with relapsed acute leukemia after allo-HSCT [26]. In addition, Levine JE et al. [34] also reported that chemotherapy and DLI with G-CSF mobilized peripherial blood cells infusion could make 27 patients $(27 / 57,47 \%)$ achieve complete remission.

Of course, there are some limitations to interpreting data from our study. The most important one is that historical cases were used as control, rather than randomized control. But, most variable were comparable between study group and historical control except for donor types $(P=0.037)$. In study group, more subjects receive a HLA-haplotype-matched transplant compared with historical control ( $66 \%$ vs. $56 \%, P=0.037$ ). However, the impact of this imbalance should be to increase rather than decrease the difficulties in interventions. As well, because multiple consolidation chemotherapy and DLIs were given based on the results of MRD tests and GvHD, therefore, it is difficult to perform randomized control study.

\section{Conclusion}

These data confirmed that after induction chemotherapy and DLI, MRD test results and GvHD-guided multiple consolidation chemotherapy and DLIs reduced CIR and improved LFS and survival in patients with relapsed acute leukemia post-transplant.

\section{Acknowledgements}

This manuscript has been revised by Prof. Robert peter Gale.

\section{Funding}

This study was supported by National Natural Science Foundation of China (Grant No. 81400142), The Key Program of National Natural Science Foundation of China (Grant No. 81230013), and Health Science Promotion Project of Beijing (project TG-2015-003).

Availability of data and materials Not applicable. 


\section{Authors' contributions}

$\mathrm{X}$-jH designed the research. C-hY analyzed the data and prepared the typescript The other authors provided the subject data. All authors read and approved the final manuscript.

\section{Competing interests}

The authors declare that they have no competing interests.

\section{Consent for publication}

Not applicable.

\section{Ethics approval and consent to participate}

The study was approved by the Ethics Committee of Peking University People's Hospital and written informed consent was obtained from all subjects in accordance with the Declaration of Helsinki.

\section{Received: 1 August 2016 Accepted: 6 September 2016} Published online: 15 September 2016

\section{References}

1. Rubio MT, Savani BN, Labopin M, Piemontese S, Polge E, Ciceri F, Bacigalupo A, Arcese W, Koc Y, Beelen D, Gülbas Z, Wu D, Santarone S, Tischer J, Afanasyev B, Schmid C, Giebel S, Mohty M, Nagler A. Impact of conditioning intensity in T-replete haplo-identical stem cell transplantation for acute leukemia: a report from the acute leukemia working party of the EBMT. J Hematol Oncol. 2016:9:25-37.

2. Pidala J, Kim J, Anasetti C, Kharfan-Dabaja MA, Nishihori T, Field T, Perkins J, Perez L, Fernandez HF. Pharmacokinetic targeting of intravenous busulfan reduces conditioning regimen related toxicity following allogeneic hematopoietic cell transplantation for acute myelogenous leukemia. J Hematol Oncol. 2010;3:36-45.

3. Schmid C, Labopin M, Nagler A, Bornhäuser M, Finke J, Fassas A, Volin L, Gürman G, Maertens J, Bordigoni P, Holler E, Ehninger G, Polge E, Gorin NC, Kolb HJ, Rocha V, EBMT Acute Leukemia Working Party. Donor lymphocyte infusion in the treatment of first hematological relapse after allogeneic stemcell transplantation in adults with acute myeloid leukemia: a retrospective risk factors analysis and comparison with other strategies by the EBMT Acute Leukemia Working Party. J Clin Oncol. 2007;25(31):4938-45.

4. Yan CH, Wang JZ, Liu DH, Xu LP, Chen H, Liu KY, Huang XJ. Chemotherapy followed by modified donor lymphocyte infusion as a treatment for relapsed acute leukemia after haploidentical hematopoietic stem cell transplantation without in vitro T-cell depletion: superior outcomes compared with chemotherapy alone and an analysis of prognostic factors. Eur J Haematol. 2013:91(4):304-14.

5. Zhao XS, Liu YR, Zhu HH, Xu LP, Liu DH, Liu KY, Huang XJ. Monitoring MRD with flow cytometry: an effective method to predict relapse for ALL patients after allogeneic hematopoietic stem cell transplantation. Ann Hematol. 2012;91(2):183-92

6. Zhao XS, Jin S, Zhu HH, Xu LP, Liu DH, Chen H, Liu KY, Huang XJ. Wilms' tumor gene 1 expression: an independent acute leukemia prognostic indicator following allogeneic hematopoietic SCT. Bone Marrow Transplant. 2012:47(4):499-507.

7. Zhao XS, Yan CH, Liu DH, Xu LP, Liu YR, Liu KY, Qin YZ, Wang Y, Huang XJ. Combined use of WT1 and flow cytometry monitoring can promote sensitivity of predicting relapse after allogeneic HSCT without affecting specificity. Ann Hematol. 2013;92(8):1111-9.

8. Yan CH, Liu DH, Liu KY, Xu LP, Liu YR, Chen H, Han W, Wang Y, Qin YZ, Huang XJ. Risk stratification-directed donor lymphocyte infusion could reduce relapse of standard-risk acute leukemia patients after allogeneic hematopoietic stem cell transplantation. Blood. 2012;119(14):3256-62.

9. Mo XD, Zhang XH, Xu LP, Wang Y, Yan CH, Chen H, Chen YH, Han W, Wang FR, Wang JZ, Liu KY, Huang XJ. Salvage chemotherapy followed by granulocyte colony-stimulating factor-primed donor leukocyte infusion with graft-vs.-host disease control for minimal residual disease in acute leukemia/myelodysplastic syndrome after allogeneic hematopoietic stem cell transplantation: prognostic factors and clinical outcomes. Eur J Haematol. 2016;96(3):297-308.

10. Yan C, Xu L, Liu D, Chen H, Wang Y, Liu K, Huang X. Immunosuppression for 6-8 weeks after modified donor lymphocyte infusion reduced acute graft-versus-host disease without influencing graft-versus-leukemia effect in haploidentical transplant. Chin Med J (Engl). 2014;127(20):3602-9.
11. Huang XJ, Wang Y, Liu DH, Xu LP, Liu KY, Chen H, Chen YH, Han W, Shi HX. Administration of short-term immunosuppressive agents after DLI reduces the incidence of DLI associated acute GVHD without influencing the GVL effect. Bone Marrow Transplant. 2009;44(5):309-16.

12. Wang YZ, Liu YR, Zhu HH, Wu HH, Cao H, Chan Y, Hao L, Jiang B, Huang XJ. Prognostic significance of minimal residual disease detected by multiparameter flow cytometry in acute myeloid leukemia. Zhongguo Shi Yan Xue Ye Xue Za Zhi. 2009;17(3):551-6.

13. Chang $Y$ J, Zhao XY, Xu LP, Zhang XH, Wang Y, Han W, Chen H, Wang FR, Mo XD, Zhang YY, Huo MR, Zhao XS, Y K, Liu KY, Huang XJ. Donor-specific anti-human leukocyte antigen antibodies were associated with primary graft failure after unmanipulated haploidentical blood and marrow transplantation: a prospective study with randomly assigned training and validation sets. J Hematol Oncol. 2015;8:84-94.

14. Lai YR, Chen YH, Hu DM, Jiang M, Liu QF, Liu L, Hou J, Schwarzenberger P, Li QC, Zhang ZM, Liu KY, Huang XJ. Multicenter phase ii study of a combination of cyclosporine a, methotrexate and mycophenolate mofetil for GVHD prophylaxis: results of the Chinese Bone Marrow Transplant Cooperative Group (CBMTCG). J Hematol Oncol. 2014;7(1):59-71.

15. Lu DP, Dong L, Wu T, Huang XJ, Zhang MJ, Han W, Chen H, Liu DH, Gao ZY, Chen YH, Xu LP, Zhang YC, Ren HY, Li D, Liu KY. Conditioning including antithymocyte globulin followed by unmanipulated HLA-mismatched/ haploidentical blood and marrow transplantation can achieve comparable outcomes with HLA-identical sibling transplantation. Blood. 2006; 107(8):3065-73.

16. Tomas ED, Storb R, Clift RA, Fefer A, Johnson FL, Neiman PE, Lerner KG, Glucksberg H, Buckner CD. Bone marrow transplantation. N Engl J Med. 1975;292(17):895-902.

17. Filipovich $A H$, Weisdorf $D$, Pavletic $S$, Socie $G$, Wingard JR, Lee SJ, Martin $P$, Chien J, Przepiorka D, Couriel D, Cowen EW, Dinndorf P, Farrell A, Hartzman R, Henslee-Downey J, Jacobsohn D, McDonald G, Mittleman B, Rizzo JD, Robinson M, Schubert M, Schultz K, Shulman H, Turner M, Vogelsang G, Flowers ME. National Institutes of Health consensus development project on criteria for clinical trials in chronic graft-versus-host disease: I. Diagnosis and staging working group report. Biol Blood Marrow Transplant. 2005; $11(12): 945-56$.

18. Grubovikj RM, Alavi A, Koppel A, Territo M, Schiller GJ. Minimal residual disease as a predictive factor for relapse after allogeneic hematopoietic stem cell transplant in adult patients with acute myeloid leukemia in first and second complete remission. Cancers (Basel). 2012;4(2):601-17.

19. Wertheim GB, Bagg A. Minimal residual disease testing to predict relapse following transplant for AML and high-grade myelodysplastic syndromes. Expert Rev Mol Diagn. 2011;11(4):361-6.

20. van de Donk NW, Kröger N, Hegenbart U, Corradini P, San Miguel JF, Goldschmidt H, Perez-Simon JA, Zijlmans M, Raymakers RA, Montefusco V, Ayuk FA, van Oers MH, Nagler A, Verdonck LF, Lokhorst HM. Prognostic factors for donor lymphocyte infusions following non-myeloablative allogeneic stem cell transplantation in multiple myeloma. Bone Marrow Transplant. 2006;37(12):1135-41.

21. Raiola AM, Van Lint MT, Valbonesi M, Lamparelli T, Gualandi F, Occhini D, Bregante S, di Grazia C, Dominietto A, Soracco M, Romagnani C, Vassallo F, Casini M, Bruno B, Frassoni F, Bacigalupo A. Factor predicting response and graft-versus-host disease after donor lymphocyte infusion: a study on 593 infusions. Bone Marrow Transplant. 2003;31(8):687-93.

22. Yan CH, Liu DH, Xu LP, Liu KY, Zhao T, Wang Y, Chen H, Chen YH, Han W, Huang XJ. Modified donor lymphocyte infusion-associated acute graft-versus-host disease after haploidentical T-cell-replete hematopoietic stem cell transplantation: incidence and risk factors. Clin Transplant. 2012;26(6):868-76.

23. Huang XJ, Chang YJ, Zhao XY. In vivo induction of T-cell hyporesponsiveness and alteration of immunological cells of bone marrow grafts using granulocyte colony-stimulating factor. Haematologica. 2004;89(12):1517-24.

24. Huang XJ, Chang YJ, Zhao XY. Maintaining hyporesponsiveness and polarization potential of T cells after in vitro mixture of G-CSF mobilized peripheral blood grafts and G-CSF primed bone marrow grafts in different proportions. Transpl Immunol. 2007;17(3):193-7.

25. Morris ES, MacDonald KP, Rowe $V$, Banovic T, Kuns RD, Don AL, Bofinger HM, Burman AC, Olver SD, Kienzle N, Porcelli SA, Pellicci DG, Godfrey DI, Smyth MJ, Hill GR. NKT cell-dependent leukemia eradication following stem cell mobilization with potent G-CSF analogs. J Clin Invest. 2005: 115(11):3093-103 
26. Huang XJ, Guo NL, Ren HY, Zhang YC, Gao ZY, Xu LP, Lu DP. The comparison of GVL effects between the patients receiving donor peripheral blood stem cells and donor lymphocytes after allogeneic bone marrow transplantation. J Peking Univ (health science). 2003;35(1):103-7.

27. Alessandrino EP, Bernasconi P, Caldera D, Colombo A, Malcovati L, Martinelli G, Bonfichi M, Pagnucco G, Salvaneschi L, Bernasconi C. Chemotherapy and donor peripheral blood progenitor cells for acute leukemia in early relapse after allogeneic bone marrow transplantation. Bone Marrow Transplant. 1999;23(6):607-12.

28. Mo XD, Zhang XH, Xu LP, Wang Y, Yan $C H$, Chen $H$, Chen YH, Han W, Wang FR, Wang JZ, Liu KY, Huang XJ. Interferon-a: a potentially effective treatment for minimal residual disease in acute leukemia/myelodysplastic syndrome after allogeneic hematopoietic stem cell transplantation. Biol Blood Marrow Transplant. 2015;21(11):1939-47.

29. Mo XD, Zhao XY, Xu LP, Liu DH, Zhang XH, Chen H, Wang Y, Huang X. Interferon a: the salvage therapy for patients with unsatisfactory response to minimal residual disease-directed modified donor lymphocyte infusion. Chin Med J (Engl). 2014;127(14):2583-7.

30. Chueh HW, Lee SH, Sung KW, Yoo KH, Koo HH. Second allogeneic stem cell transplantation in hematologic malignancies: a single-center experience. J Pediatr Hematol Oncol. 2013;35(6):424-9.

31. Christopeit M, Kuss O, Finke J, Bacher U, Beelen DW, Bornhauser M, Schwerdtfeger R, Bethge WA, Basara N, Gramatzki M, Tischer J, Kolb HJ, Uharek L, Meyer RG, Bunjes D, Scheid C, Martin H, Niederwieser D, Kröger N, Bertz H, Schrezenmeier H, Schmid C. Second allograft for hematologic relapse of acute leukemia after first allogeneic stem-cell transplantation from related and unrelated donors: the role of donor change. J Clin Oncol. 2013;31(26):3259-71.

32. Chen YH, Xu LP, Chen H, Liu DH, Zhang XH, Han W, Wang FR, Wang JZ, Wang Y, Zhao T, Chen Y, Zhang YY, Yan CH, Sun YQ, Liu KY, Huang XJ. The efficacy and safety of second allogeneic hematopoietic stem cell transplantation for post-transplant hematologic malignancies relapse. Zhonghua Nei Ke Za Zhi. 2011;50(6):489-91.

33. Collins Jr RH, Shpilberg O, Drobyski WR, Porter DL, Giralt S, Champlin R, Goodman SA, Wolff SN, Hu W, Verfaillie C, List A, Dalton W, Ognoskie N, Chetrit A, Antin JH, Nemunaitis J. Donor leukocyte infusions in 140 patients with relapsed malignancy after allogeneic bone marrow transplantation. J Clin Oncol. 1997;15(2):433-44.

34. Levine JE, Braun T, Penza SL, Beatty P, Cornetta K, Martino R, Drobyski WR, Barrett AJ, Porter DL, Giralt S, Leis J, Holmes HE, Johnson M, Horowitz M, Collins Jr RH. Prospective trial of chemotherapy and donor leukocyte infusions for relapse of advanced myeloid malignancies after allogeneic stem-cell transplantation. J Clin Oncol. 2002;20(2):405-12.

35. Slovak ML, Kopecky K, Cassileth PA, Harrington DH, Theil KS, Mohamed A, Paietta E, Willman CL, Head DR, Rowe JM, Forman SJ, Appelbaum FR. Karyotypic analysis predicts outcome of preremission and postremission therapy in adult acute myeloid leukemia: a Southwest Oncology Group/ Eastern Cooperative Oncology Group Study. Blood. 2000;96(13):4075-83.

36. Moorman AV, Harrison CJ, Buck GAN, Richards SM, Secker-Walker LM, Martineau M, Vance GH, Cherry AM, Higgins RR, Fielding AK, Foroni L, Paietta E, Tallman MS, Litzow MR, Wiernik PH, Rowe JM, Goldstone AH, Dewald GW, Adult Leukaemia Working Party, Medical Research Council/ National Cancer Research Institute. Karyotype is an independent prognostic factor in acute lymphoblastic leukaemia: analysis of cytogenetic data from patients treated on the MRC UKALL XII/ECOG 2993 trial. Blood. 2007;109(8):3189-97.

\section{Submit your next manuscript to BioMed Central and we will help you at every step:}

- We accept pre-submission inquiries

- Our selector tool helps you to find the most relevant journal

- We provide round the clock customer support

- Convenient online submission

- Thorough peer review

- Inclusion in PubMed and all major indexing services

- Maximum visibility for your research

Submit your manuscript at www.biomedcentral.com/submit 